\title{
Modeling Associated with Picky Eating Behavior on Stunted Children
}

\author{
Bertakalswa Hermawati ${ }^{1}$, Oktia Woro Kasmini Handayani ${ }^{2}$, Dhevy Fajriyatul \\ Umma $^{3}$, Adinda Yustika Seftiani ${ }^{4}$ \\ \{bertahermawati@gmail.com ${ }^{1}$, oktia_woro@yahoo.co.id ${ }^{2}$, dhevyfajriyatul14@gmail.com ${ }^{3}$ \}
}

Universitas Negeri Semarang, Semarang, Indonesia ${ }^{1,2,3,4}$

\begin{abstract}
Long term consequence of picky eater is under optimal growth and development difficulties. The objectives of this study were to determine the modeling associated with picky eating behavior on stunted children. A questionnaire was used to conduct a cross-sectional study of 36 mothers with stunted children under five years old who were picky eater behavior. Data collected included: socio-demographic, modeling, and picky eater behavior. The study design was case-control, Data analysis using chi-square. The result showed that the modeling associated with picky eating significantly $(\mathrm{p}=0.040), \mathrm{p}<0.050$. The findings suggest that all family members may intentionally and unintentionally model healthy and unhealthy foods.
\end{abstract}

Keywords: modeling, picky eater, stunted children

\section{Introduction}

Stunting is a major nutrition issue facing Indonesia today. World Health Organization (WHO) states Indonesia is the third country with the highest prevalence of stunting in the Southeast Asia / South-East Asia Regional (SEAR) region. There were $36.4 \%$ of stunted children in Indonesia in 2005-2017 [1]. Stunting is the impaired growth and development of children. A child is defined as stunting if their height for age is more than two standard deviations below the median of the World Health Organization (WHO) Child Growth Standards [2]. It is caused by several conditions such as poor nutrition, recurrent infections, and inadequate psychosocial stimulation.

One of the factors that contribute to stunted growth and development is an inadequate infant and young child feeding [2] because of a picky eater. Although picky eaters are a common behavior that occurs during childhood, picky eaters have become a serious problem in nutrient intake in some children. Several studies showed that there is a correlation between picky eaters and stunted children. $77 \%$ of stunted children under five are picky eater [3]. According to recent studies, a decrease in appetite and intake due to the behavior resulting in children under five becoming lack of energy and nutrients that inhibit growth [3][4]. Besides, a lower intake of vitamin E, vitamin C, folate, and fiber in children with a picky eater can cause immune responses and a weak digestive system [5]. 
ISPHE 2020, July 22, Semarang, Indonesia Copyright (c) 2020 EAI

DOI 10.4108/eai.22-7-2020.2300257 

Picky eating is a common behavior, also known as fussy eating, selective eating, faddy eating, and choosy eating [5-7]. Others said that picky eater is defined as an unwillingness to eat familiar foods or try new foods [4,7] which are characterized by various reactions to refuse to eat certain types of foods, (texture, color, or mouthfeel), only wants to eat the same foods over and over and food are cooked with a certain method or booth. The child's response also varies in eating behavior, such as feeling full quickly, eat slow, talkative, fussy about food, less responsive, and do not enjoy eating [8]. Studies on this subject revealed that children tend to dislike vegetables and prefer not to eat fruits, potatoes, and meat [5]. The prevalence of picky eating from 6 to $50 \%$ [9]. In Indonesia, the prevalence of stunting about 58\% [4]. Studies in China showed that the prevalence of picky eating as high as $54 \%$ among children under five and in Singapore $49.2 \%$ and Vietnam $25.3 \%$ [10].

Picky eating can cause distress in parents, and in their attempts to increase healthy food intake by some strategies. Regardless of the strategy to handle fussy eaters, parents as role models are a factor that influences healthy eating habits in children. Albert Bandura on his Social Learning Theory said that a process of observational learning relies on the parent to encourage and facilitate behavior within the child, with the consequence of the behavior becoming habitual is modeling [11]. Parental food behavior was considered to have both positive and negative influences on individual eating habits [12]. Introducing children to new foods within a positive atmosphere may encourage taste acquisition and promote more varied and healthy food preferences [13]. Similarly, Savage [14] said parents have the power to shape children's early experiences with food and eating. Parental influence to select the foods of the family diet, serve as models of eating that children learn to emulate, and use feeding practices to stimulate the development of culturally appropriate eating patterns and behaviors in their children.

The study aimed to determine the modeling associated with picky eating behavior on stunted children in Demak region. By understanding the relationship between these factors, we can examine the effective improvement strategies of children feeding practices.

\section{Methods}

The population was mothers with stunted children in Demak region. The sampling method used was purposive sampling. The sample in this study was 36 mothers with stunted children under five and lived in three villages: Kembangan, Tridonorejo, and Tlogoboyo.

The inclusion criteria in this study were mothers with stunted children who lived in the study area and were willing to be involved in this study. Mothers are not included in this study were mothers with stunted children, lived in the study area but were willing to be involved in this study

This study uses a cross-sectional design. This study uses a questionnaire instrument to determine the modeling and picky eater. Data were obtained by interviewing mothers using the instrument's guide. All participants were interviewed to obtain data 
on socio-demography, modeling, and picky eater. The variables of socio-demography have created the category of stunting, sex, and socio-economic status. The questionnaire for modeling addressed two general areas (people who are role models and food preferences). All the data collected from the study was obtained through face-to-face interviews with mothers. This interview takes about 20 minutes. The picky eater set was developed by using several variables analysis (frequencies, types of food like, and dislike). The frequency variable on picky eater was ranked in ascending order and then categorized into quantile (1) never, (2) seldom, (3) sometimes (4) often. Data analysis in this study uses quantitative methods and uses a chi-square test to determine the relationship between two nominal variables.

\section{$3 \quad$ Results and discussion}

36 parent participants completed the instrument. The subject characteristics are presented in the following table 1.

Table 1. Demographic Characteristics of Respondent

\begin{tabular}{llll}
\hline & Variable & n: $\mathbf{3 6}$ & $\mathbf{\%}$ \\
\hline Stunting & Severe Stunted & 9 & $25 \%$ \\
& Stunted & 27 & $75 \%$ \\
Sex & Boy & 19 & $53 \%$ \\
\multirow{2}{*}{ Socio-economic status } & Girls & 17 & $47 \%$ \\
& Middle high & 1 & $1 \%$ \\
& Low & 35 & $99 \%$ \\
\hline
\end{tabular}

Note: Income level based on Regional Minimum Wages at Demak, Central Java Province, Indonesia. Middle Low: Less than IDR 2.420.000. Middle High: More than IDR 2.420.000

Based on this data, $25 \%$ severely stunted children who were picky eater behavior, and $75 \%$ stunted children who were picky eater behavior, and $53 \%$ of boys are stunted who were picky eater behavior and $47 \%$ of girls are stunted who were picky eater behavior. Most respondents are low socio-economic status (99\%), and 1\% is middle high.

Table 2. Characteristics of Picky Eater

\begin{tabular}{lllll}
\hline & & Variable & Respondent & $\%$ \\
\hline $\begin{array}{l}\text { Child's } \\
\text { food }\end{array}$ response & to & Tantrum (angry, crying) & 14 & 44 \\
(n: 32) & & Refuse to open mouth & 7 & 22 \\
& & Feeding Distraction & 6 & 19 \\
& & Food refusal through a verbal reaction & 3 & 9 \\
& & Self-induced vomiting & 1 & 3 \\
& & Pushes foods around the plate & 1 & 3 \\
\hline $\begin{array}{l}\text { Reasons the child } \\
\text { fuses to eat }\end{array}$ & re- & Dislike food & 26 (fishy: 2) & 81 \\
(n: 32) & & Reluctant to eat rice & 3 & 9 \\
& & Dislike taste & 2 & 6 \\
& It hard to floss the tiny pieces of food & 1 & 4 \\
\hline Food likes & that gets stuck in between his teeth & & 41 \\
\hline
\end{tabular}




\begin{tabular}{|c|c|c|c|}
\hline \multirow[t]{7}{*}{ (n: 32) } & Fish & 8 & 25 \\
\hline & Soy (soy sauce, tofu, and tempeh) & 3 & 9 \\
\hline & Candy & 3 & 9 \\
\hline & Chicken & 2 & 7 \\
\hline & Sausage & 1 & 3 \\
\hline & Biscuit & 1 & 3 \\
\hline & Snack & 1 & 3 \\
\hline \multirow{9}{*}{$\begin{array}{l}\text { Food dislikes } \\
(\mathbf{n}: 32)\end{array}$} & Rice & 7 & 22 \\
\hline & Fish & 5 & 16 \\
\hline & Soy (Tofu and tempeh) & 9 & 28 \\
\hline & Fruit & 3 & 9 \\
\hline & Chicken & 3 & 9 \\
\hline & Egg & 1 & 3 \\
\hline & Spicy foods & 2 & 7 \\
\hline & Coconut milk & 1 & 3 \\
\hline & Vegetable & 1 & 3 \\
\hline \multirow{4}{*}{$\begin{array}{l}\text { Role model } \\
\text { children } \\
(\mathbf{n}: \mathbf{1 7})\end{array}$} & Mother & 9 & 53 \\
\hline & Father & 6 & 35 \\
\hline & Siblings & 1 & 6 \\
\hline & All family member & 1 & 6 \\
\hline \multirow{11}{*}{$\begin{array}{l}\text { Food /Drink choice. } \\
\text { Imitation of role mod- } \\
\text { els' to eat food } \\
(\mathrm{n}: 17)\end{array}$} & Coffee & 5 & 31 \\
\hline & Ice & 3 & 19 \\
\hline & Chicken & 1 & 6 \\
\hline & Fried food & 1 & 6 \\
\hline & Snack & 1 & 6 \\
\hline & Kebab & 1 & 6 \\
\hline & Egg & 1 & 6 \\
\hline & Fruit & 1 & 6 \\
\hline & Instant noodles & 1 & 6 \\
\hline & Sunflower seed & 1 & 6 \\
\hline & Fish & 1 & \\
\hline \multirow{4}{*}{$\begin{array}{l}\text { Food/Drink choice. } \\
\text { Imitation of role models' } \\
\text { not to eat food } \\
\text { (n:17) }\end{array}$} & Fruit & 9 & 53 \\
\hline & Vegetables & 5 & 29 \\
\hline & Fish & 2 & 12 \\
\hline & Ice & 1 & 6 \\
\hline
\end{tabular}

This study revealed that the child refuses the food with many reactions: $44 \%$ tantrum (angry, crying), 22\% refuse to open mouth, 19\% feeding distraction, and 15\% others (food refusal through verbal reaction, self-induced vomiting, pushes foods around the plate). Besides, the reasons the child refuses to eat are $81 \%$ dislike food, $9 \%$ reluctant to eat rice, $6 \%$ dislike taste, and $4 \%$ it hard to floss the tiny pieces of food that get stuck in between his teeth. The study also found that the children like the food such as $41 \%$ egg, $25 \%$ fish, 3\% candy/chocolate, and 3\% soy (soy sauce, tofu, and tempeh) and dislike the food such as $28 \%$ soy, $22 \%$ rice and $16 \%$ fish. Role models to imitate the eating behavior are $53 \%$ mother, $35 \%$ father, $6 \%$ siblings, and $6 \%$ all family members. Besides, the food choice that the children imitate' to eat and drink is ice and coffee, the food choice that the children imitate not to eat is $53 \%$ fruit, $29 \%$ vegetables, and $12 \%$ fish. 
Table 3. Statistic Result Test between modeling and picky eater

\begin{tabular}{|c|c|c|c|}
\hline \multirow[t]{2}{*}{ Variable } & \multicolumn{2}{|c|}{$\begin{array}{c}\text { Total numbers of Picky } \\
\text { Eater's cases }\end{array}$} & \multirow[t]{2}{*}{$\mathbf{P}$} \\
\hline & Yes & No & \\
\hline $\begin{array}{l}\text { Role model }(n=36) \\
\text { Yes }(n=17) \\
\text { No }(n=19)\end{array}$ & $\begin{array}{l}13(76 \%) \\
19(100 \%)\end{array}$ & $\begin{array}{r}4(24 \%) \\
0(0 \%) \\
\end{array}$ & 0.040 \\
\hline
\end{tabular}

With a total of 36 respondents, it was found that there was an association between modeling and picky eater in children under five significantly with a value of $\mathrm{p}<0.05$.

Picky eating is defined as "sometimes" or "often" does not eat well and refuses to eat [6]. It is characterized by an unwillingness to eat familiar foods or to try new foods, as well as strong food preferences [15]. This study revealed $89 \%$ of stunted children under five years old were picky eater. There are many studies on the prevalence of picky eating in childhood, and a large variation in prevalence was found [16]. The prevalence of picky eating in Asia children above 50\% [10,17]. This study showed that the children display refuse to eat such as self-induced vomiting, feeding distraction, food refusal through verbal reaction, tantrum, refuse to open mouth, pushes foods around the plate.

Based on this study, there are few reasons why the children are refusing to eat a certain food: dislike the food, dislike the taste, and reluctant to eat rice. This study revealed the most favorite food such as egg, fish, soy (tofu, tempeh, soy sauce), and candy. On another side, this study found that different types of food refusal by some children such as rice, fish, and soy (tofu and tempeh). Picky eater often has inadequacy of some nutrients, reduced energy intake, eat fewer fruits and vegetables, and have lower intakes of dietary fiber $[7,18]$.

As a result, many healthy nutrients are not absorbed properly in children that related long-term consequences include a weakened immune system then causes the emergence of diseases in children. It can be effective for stunting. The picky eater was found in this study of stunted children. Similarly, the other study revealed picky eating was relatively prevalent among stunted Vietnamese children under five years of age [10]. This study also showed that there are two classifications of prevalence in stunting namely severe stunted and stunted. The proportions of stunted boys been higher than girls in this study. Similarly, some studies report on sex differences in stunting and find higher odds for boys than for girls [19,20]. Elsmen and Killbride said that stunting prevalence of different sex is caused by health conditions, low birth weight, and in utero health conditions. This study also found epidemiological evidence that young girls are less vulnerable to adverse health outcomes than young boys. increase the odds of stunting more for boys than for girls. Preterm-born males and those with low birth weight are worse off than their female counterparts. It means in utero health conditions are important for child health after birth [19].

The children develop picky eating habits by modeling their parents' fussy eat- ing habits. This study found that modeling is associated with a picky eater in stunted children. They learn about eating behavior from their parents, siblings, and all family. This research also showed that a mother is the most role model for the children. Indeed, mothers have an emotional attachment to their children's eating behavior. They have awareness about food and eating changes [21]. Besides, Albert Bandura in his theory, Social Learning state that most people's behavior is learned, either deliberately or inadvertently through the influence of example. This evidence suggests a good example is therefore a much better teacher than the consequences of unguided actions [22]. In line with the ecological model of developing food choices by Urie Bronfenbrenner on This Ecological Systems Theory, the interaction of different environmental factors may result in human behavior. Parents provide food environments and experiences with food and eating for their children. Children model themselves on their parents' eating behaviors, eating-related attitudes, type of food, lifestyle, and satisfaction or dissatisfaction regarding body image [21]. 


\section{Conclusions}

This study found associations between modeling and picky eater. Family feeding behavior has a significant effect on a child's food preference. To encourage their child's food preferences, all members shall utilize many diverse behaviors to get effective strategies for healthy food intake during mealtimes.

\section{Acknowledgments}

This study was funded by the Budget Implementation List (Daftar Isian Pelaksanaan Anggaran/DIPA), Sports Science Faculty, Universitas Negeri Semarang (UNNES). We would like to thank the head of Public Health Center Bonang 1, Central Java, Indonesia, all participants in this research. This article was approved by the Health Research Ethics Committee (HREC), Universitas Negeri Semarang.

\section{References}

[1] Pusat Data dan Informasi KKR. Situasi Balita Pendek (Stunting) di Indonesia. 2018.

[2] WHO. WHA Global Nutrition Targets 2025: Stunting Policy Brief. 2018.

[3] Nurmalasari Y, Utami D, Perkasa B. Picky eating and stunting in children aged 2 to 5 years in central Lampung, Indonesia. Malahayati Int J Nurs Heal Sci. 2020;03:29-34.

[4] Putri AN, Muniroh L. Hubungan Perilaku Picky eater dengan Tingkat Kecukupan Zat Gizi dan Status Gizi Anak Usia Prasekolah Di Gayungsari Correlation of Picky Eater with Intake Adequacy and Nutritional Status in Preschool-Aged Children in Gayungsari. Amerta Nutr. 2019;232-8.

[5] Wolstenholme H, Kelly C, Hennessy M, Heary C. Childhood fussy/picky eating behaviors : a systematic review and synthesis of qualitative studies. Int J Behav Nutr Phys Act. International Journal of Behavioral Nutrition and Physical Activity; 2020;1-22.

[6] Samuel TM, Musa-Veloso K, Ho M, Venditti C, Shahkhalili-Dulloo Y. A Narrative Review of Childhood Picky Eating and Its Relationship to Food Intakes, Nutritional Status, and Growth. Nutrients. 2018;10:1-30.

[7] Walton K, Kuczynski L, Haycraft E, Breen A, Haines J. Time to re-think picky eating ?: a relational approach to understanding picky eating. Int J Behav Nutr. International Journal of Behavioral Nutrition and Physical Activity; 2017;1-8.

[8] Khaq AE, Yuniastuti A, Rahayu SR. An Analysis of Picky Eater Towards Growth and Motor Development at Kebasen District Health Centre. Public Heal Perspect J. 2018;3:224-30. 
[9] Emmett PM, Hays NP, Taylor C. Antecedents of picky eating behavior in young children. Appetite. 2018;163-73.

[10] Yen HTB, Huong LT, Thang V Van, Tien HA. Picky Eating and Nutritional Status among Vietnamese Children Under Five Years of Age in Hue, Central Vietnam. Biomed J Sci Tech Res. 2019;11733-9.

[11] Palfreyman Z, Haycraft E, Meyer C. Original Article Development of the Parental Modeling of Eating Behavior Scale ( PARM ): links with food intake among children and their mothers. Matern Child Nutr. 2014;617-29.

[12] Sogari G, Velez-Argumedo C, Gómez MI, Mora C. College students and eating habits: A study using an ecological model for healthy behavior. Nutrients. 2018;10:1-16.

[13] Lyons M. Children's Picky Eating and the Role of Family Environments. J Undergrad Res. 2015;15.

[14] Savage JS, Fisher JO, Birch LL. Parental influence on eating behavior. J Law, Med Ethics. 2007;35:22-34.

[15] Taylor CM, Wernimont SM, Northstone K, Emmett PM. Picky/fussy eating in children: Review of definitions, assessment, prevalence and dietary intakes. Appetite. Elsevier ,Ltd; 2015;95:349-59.

[16] Chao H. Association of Picky Eating with Growth, Nutritional Status, Development, Physical Activity, and Health in Preschool Children. Front Pediatr. 2018;6:1-9.

[17] Xue Y, Zhao A, Cai L, Yang B, Szeto IMY, Ma D. Growth and Development in Chinese Pre- Schoolers with Picky Eating Behaviour: A Cross-Sectional Study. PLoS One. 2015;1-16.

[18] Kwon KM, Shim JE, Kang M, Paik H. Association between Picky Eating Behaviors and Nutritional Status in Early Childhood: Performance of a Picky Eating Behavior Questionnaire. Nutrients. 2017;9.

[19] Knaap I van der. The determinants of sex differences in child stunting in Sub Saharan Africa: a multilevel logistic Sub-Saharannalysis. 2018.

[20] Wamani H, Åstrøm AN, Peterson S, Tumwine JK, Tylleskär T. Boys are more stunted than girls in Sub-Saharan Africa: A meta-analysis of 16 demographic and health surveys. BMC Pediatr. 2007;7:1-10.

[21] Scaglioni S, Cosmi V De, Ciappolino V, Brambilla P, Agostoni C. Factors Influencing Children's s Eating Behaviours. Nutrients. 2018;1-17.

[22] Bandura A. Social learning: Theory. Gen. Learn. Press. 1971. p. 1-46. 